\title{
NARRAR EL MIEDO: REPRESENTACIÓN DE LA CIUDAD DE QUITO EN TRES NOVELAS ECUATORIANAS DE LOS ÚLTIMOS AÑOS
}

\author{
NARRATING FEAR: PRESENTATION OF THE CITY OF QUITO \\ IN THREE ECUADORIAN NOVELS IN THE LAST YEARS
}

\author{
Manuel Villavicencio \\ Universidad de Cuenca. Cuenca, Ecuador \\ manuel.villavicencio@ucuenca.edu.ec
}

\begin{abstract}
Resumen: En el presente ensayo se plantea analizar cómo se construye el miedo en la urbe quiteña representada en las obras Edén y Eva (2013) de Huilo Ruales; Los años perdidos (2013) de Juan Pablo Castro; y Ecuatox® (2013) de Santiago Páez, bajo el supuesto de que "no es la amenaza la que crea el miedo, sino el miedo el que crea la amenaza” (Lotman). En otras palabras, reflexionar sobre la relación secreta que vincula la construcción del miedo en la urbe quiteña contemporánea, con el establecimiento de una máquina de relatos que articula dispositivos que generan la amenaza, y cómo esta controla los cuerpos individuales y colectivos. Pero también debemos analizar, cómo los autores en sus obras tensan esta "realidad", mediante la creación/ficción de espacios, historias y personajes (locos, payasos, marginales, poetas y prostitutas) que habitan una urbe que se resiste a la visión monológica del poder. La risa, la ironía, la memoria, la ciencia ficción son dispositivos que actúan como catalizadores del contra-poder. Prácticas de resistencia que buscan la "ciudad que falta"; una dialógica, heterogénea, múltiple y libre.
\end{abstract}

Palabras clave: Ciudad, miedo, amenaza, resistencia, novela ecuatoriana reciente.

\begin{abstract}
In the present essay it is proposed to analyze how fear is built in the Quito city represented in the works Edén y Eva (2013) de Huilo Ruales; Los años perdidos (2013) de Juan Pablo Castro; y Ecuatox $\circledR$ (2013) de Santiago Páez, under the assumption that "it's not the threat that creates fear, but fear which creates the threat" (Lotman). In other words, to analyze the secret relationship that links the construction of fear in the contemporary city of Quito, through the establishment of a story machine that articulates fear-generating devices, and how it controls individual and collective bodies. However, we also have to analyze the way authors stretch this "reality" in their works, through the creation/fiction of spaces, stories, and characters (lunatics, clowns, marginalized people, poets, prostitutes,...) who live in a city that resist the monological vision of power. Laughter, irony, memory, and science fiction
\end{abstract}


are devices that work as counter-power's agents of change. These practices of resistance search for the "missing city," a dialogic, heterogeneous, multiple, and free one.

Keywords: City, fear, threat, resistance, Ecuadorian novels of recent years.

Recibido: 10.11.2016. Aceptado: 01.03.2017.

\section{Introducción: La ciudad como escenario del miedo}

El miedo es una construcción social donde las brujas son una peligrosa minoría organizada.

YURI LOTMAN

$\mathrm{U}$ NA PRIMERA entrada para la caracterización del miedo de la urbe contemporánea se relaciona con los cambios de modelo económico y su correlato en las ciudades. Esta se constituye en un espacio contradictorio: si en un principio se construyó alrededor de un centro sagrado como el templo, la plaza, por ejemplo, relegando hacia la periferia lo menos valioso y el peligro, hoy se levanta en sus suburbios las zonas residenciales, mientras que su centro deviene el deterioro, el caos, la amenaza y el miedo. Así, la ciudad invierte sistemáticamente los signos que la construyeron: sustituye la promesa de compañía por la de soledad, seguridad por temor, riqueza por miseria, belleza por mugre, pureza por contaminación. Todos estos atributos positivos son simbólicamente restituidos a la naturaleza, fuera de la periferia y en definitiva fuera del control humano. En ella se produce una rápida y arrolladora mutación de la existencia humana, que da origen

tanto a las angustias individuales como a los sufrimientos sociales y morales, como las nuevas condiciones de libertad [...] entendida como liberación de los vínculos de la sociedad "cerrada": la aldea, la comunidad familiar, el burgo tradicional tanto a las angustias individuales como a los sufrimientos sociales y morales, como las nuevas condiciones de libertad [...] entendida como liberación de los vínculos de la sociedad "cerrada": la aldea, la comunidad familiar, el burgo tradicional (Zarone, 1993: 7-9).

Una segunda propuesta de lectura se relaciona con las políticas de intervención arquitectónica y urbanística tanto públicas como privadas, que intentan paliar la creciente sensación de angustia e inseguridad urbanas 
asociada a los cambios de los estilos de vida en las metrópolis por efecto de la expansión de la violencia. Esto lleva a que las personas restrinjan su circulación en espacios públicos, eviten salir de noche o visiten ciertos barrios; se recluyan puertas adentro y busquen el esparcimiento en espacios privados. "El miedo - para Reguillo (2000)- constituye una experiencia individual que requiere, no obstante, la confirmación o negación de una comunidad de sentido" (28). Se crea el miedo al otro, al ajeno, extraño o extranjero; es decir, al que se encuentra fuera del sistema, fáciles de manipular, pues "la ansiedad acumulada tiende a descargarse contra determinados forasteros, elegidos para que personifiquen lo raro, lo inquietante, lo impenetrable de algunas costumbres, la vaguedad de ciertos peligros y amenazas" (Bauman, 2006: 27).

Una tercera aproximación busca retratar los espacios urbanos de la intervención pública, es decir, de la planeación urbana propiciada desde el Estado; a partir del modelo de un capitalismo desregulado. Las grandes autopistas "concesionadas" se constituyen en los referentes urbanos más reconocibles de la intervención pública en la ciudad, estableciendo los límites de cemento y hormigón. La calle y los espacios públicos se han convertido en escenarios amenazantes y sospechosos, donde reina la delación. Espacios semejantes a los narrados por Roberto Bolaño, Ricardo Piglia, Edmundo Paz Soldán, Jorge Volpi, entre otros, que se constituyen, según Virilio (2011), en escrituras del desastre.

Esta lógica de privatización, unida a la creciente sensación de inseguridad mediática, confabula de forma que las antiguas zonas de la ciudad destinadas a la convivencia y al efectivo ejercicio ciudadano, devienen en territorios del miedo y la tecnología de vigilancia actual, pues su concepción se desarrolla en dos frentes "y sirve a dos objetivos estratégicamente opuestos: por un lado, el confinamiento (o "mantener dentro de la valla"), y por otro, el de la exclusión (o "mantener más allá de la valla")" (Bauman, 2013: 72). Este proceso ha sido caracterizado como un "asalto al espacio público", en el sentido de apropiación del espacio público. La particularidad de nuestras ciudades -aclara Sánchez- "es más cercana a la barbarie que a la modernidad. Ciudades que generan, organizan y jerarquizan la brutalidad y la violencia de todo tipo" (2002: 314).

La ciudad, a lo largo de su historia, se ha convertido en la víctima del miedo donde podemos distinguir dos casos: Por un lado, el colectivo está 
amenazado por un tipo de peligro específico (la peste negra, epidemias, invasiones, guerras...), donde el miedo tiene un destinatario real y el objeto que lo genera es el mismo. Por otro lado, la sociedad es presa de un ataque de miedo, cuyas causas sociales desconocen. Los destinatarios son engañados, pues "no es la amenaza la que genera el miedo, sino el miedo el que genera la amenaza" (Lotman, 2008: 6). El miedo resulta ser una construcción social, una epidemia que afecta a todos, a tal punto que según Jean Delumeau (2001) existe una repetición periódica de los miedos en las distintas épocas y sociedades, demostrando así su carácter cíclico, pero también "resistencias, practicando contrapoder, ensayando nuevas articulaciones" (Rodríguez, 2014: 19).

En esta perspectiva, algunos estudiosos vinculan la amenaza y el miedo como formas de habitar lo contemporáneo. Es decir, vivir el miedo y la amenaza supone ser presa de una máquina siniestra que provoca sensaciones personales y colectivas de incertidumbre frente al presente. Mongardini (2007) afirma que estos son instrumentos de control social de los cuales se sirven los gobiernos para tener al pueblo a su disposición. Reguillo (2000), por su parte, sostiene que el miedo es una imposición cultural, depende dónde y en qué contexto nacemos para temer a ciertas cosas, pues hay diversas formas de percibir al mismo fenómeno, lo cual modifica la percepción de la amenaza. Sin embargo, el miedo no se queda en la persona sino se colectiviza en la sociedad, por lo que los gobiernos han tomado ventaja de ello y para controlar a los ciudadanos ofrecen una falsa seguridad, a través de la construcción simbólica de inminentes amenazas que aletargan y ponen a todos en sus manos. Bauman (2006) considera al miedo como un dispositivo de control social "escurridizo y omnipresente, que se filtra por cualquier recoveco o rendija, mana de la calle, de la obscuridad, de la pantalla del televisor, de los espacios tumultuosos, de los conocidos y desconocidos" (13).

En la política es cuestión de saber explotar al miedo, y aquel hombre o grupo que sepa cómo hacerlo impondrá su domino:

El ejercicio del poder necesita de una sociedad que se sienta temerosa, insegura y vulnerable; mantenerla así hace a la gente sumisa y consolidar la eficacia del poder. Sin embargo, no hay que olvidar que la expresión del poder es cada vez menos visible, y por ello su influencia es difícil de conocer, de discernir y de resistir. El ejercicio del poder es paulatina- 
mente más elusivo e insidioso, está en cualquier lugar, en ninguno, es ubicuo, ausente, invisible... (Cortés, 2010: 10).

Los miedos impuestos o creados, finalmente desembocan en la forma de actuar de la persona frente a lo que considera una amenaza, en cualquier sentido. La mayoría de los estudiosos concluyen que no hay tipos de miedo, sino solo formas de percibirlo. Sin embargo, al igual que Bauman (2007), coinciden que

El miedo constituye, posiblemente, el más siniestro de los múltiples demonios que anidan en las sociedades abiertas de nuestro tiempo. Pero son la inseguridad del presente y la incertidumbre sobre el futuro las que incuban y crían nuestros temores más imponentes e insoportables. La inseguridad y la incertidumbre nacen, a su vez, de la sensación de impotencia: parece que hemos dejado de tener el control como individuos, como grupos, como colectivo (42).

En el contexto actual existen inevitables lugares comunes a la hora de abarcar el tema del miedo y los dispositivos de control en la urbe. En primer lugar, resalta la idea en torno al panóptico de Bentham y retomado por Foucault. La ciudad controlada de Deleuze, vigilada y teledirigida por Virilio. Bauman nos habla en su Vigilancia líquida (2013) del post-panóptico. Las formas de control de la modernidad han sido sustituidas y esto se debe al gran auge de las tecnologías y sus bases de datos como tónica en las ciudades actuales. Antes, las formas del control social consistían en la dominación ideológica, mediante medios tangibles, como reglas claras o ideologías basadas en cultos religiosos de castigo y sumisión, así como también las fuerzas militares y policiales. Fueron efectivas en su momento, pero con la tecnificación y la visión foucaultiana han servido de antecedentes para dominar al sujeto como una cifra maleable al momento de análisis, represión y mantención social, pues "la evolución social está originando nuevas estructuras políticas y culturales, nuevas maneras de entender el mundo, y también nuevas fuentes de poder" (Cortés, 2010: 8) y, claro, nuevos dispositivos de control.

Si antes la ciudad real fue administrada desde la escritura por los intelectuales de la ciudad letrada, hoy la ciudad real responde a los diseños culturales de los media y del Internet. Ellos traducen en toda América Latina 
un modo de ser, concebir a la política, la ética, la identidad, la nacionalidad, la sexualidad, la entretención y la vida cotidiana. En lugar de las murallas que antes guardaban las ciudades, hoy tenemos los muros de cada domicilio, condominio o residencia universitaria, aislando a los ciudadanos entre sí y protegiéndolos de un enemigo frecuente, cuyo rostro múltiple pertenece a cualquiera y amenaza la vida de todos.

La ciudad de Quito no podía escapar de esta lógica globalizante. Durante la primera mitad del siglo XX se produjeron cambios significativos en la capital ecuatoriana, hasta el punto que avanzado los setentas nos encontramos frente a dos ciudades: la Quito vieja, anclada en la historia y poblada por la marginalidad; y una Quito moderna, que huye de su pasado (Ortega, 2002), y se extiende larga y seductora hacia los valles donde la vida es mejor, lejos de la hediondez de la historia y contaminación del Centro Histórico. Un espacio en medio de grandes autopistas, aeropuertos, centros comerciales que se conectan directamente con universidades costosas; edificios inteligentes y ecológicos resguardados por vigilantes privados que impiden el acceso de cualquier intruso.

En este sentido, a continuación abordaremos tres relatos contemporáneos de la literatura ecuatoriana en las que se representa el imaginario urbano quiteño que ha sido tomado por el miedo político, cultural, económico y civil. Ciudad horrible, ciudad del mal, ciudad enferma, ciudad sitiada... son algunos de los epítetos que emplean los personajes para definir esta urbe habitada por malas intenciones, culpables, delitos y designios criminales. La selección del corpus se realizó considerando algunos criterios: a) la importancia de los escritores y sus obras en el actual imaginario letrado ecuatoriano; b) su propuesta estético-literaria merece ser conocida por el lector hispanoamericano, para incluir al Ecuador en sus estudios; y c) su pertinencia con el contexto social, cultural y político que vive el Ecuador en los últimos diez años, evidenciándose las tensiones con el poder del Estado.

En primer lugar, cómo el miedo y la amenaza fabrican atmósferas del conformismo y la mediocridad; personajes sin escape que solo esperan la muerte para aligerar su pesada carga. Nos referimos a Los años perdidos, de Juan Pablo Castro, cuyo protagonista echa mano de la memoria para recobrar, aparentemente, la felicidad que vivió en Quito y Lisboa. Sin embargo, las dos ciudades son espacios "para el olvido", provocan la desdicha 
del re-encuentro y re-conciliación con el sujeto fragmentado que espera al final de sus días ser encontrado muerto en su miserable habitación.

Posteriormente, analizaremos la ciudad-infierno narrado en Edén y Eva, de Huilo Ruales. Obra potente de uno de los mejores escritores ecuatorianos en la actualidad, donde se narra el confinamiento de Eva, su personaje principal, en una ciudad que imposibilita su liberación. Ciudad de cemento, ciudad de hormigón, ciudad fea, ciudad siniestra... son algunos de los epítetos que se utilizan para caracterizar esta urbe que mira a la diversidad como una especie que tiene que estar controlada por el ojo del panóptico.

Finalmente, la ciudad post-apocalíptica de Santiago Páez narrada en Ecuatox@. Novela provocadora y atrevida que ha sido leída y analizada por pocos en el Ecuador, quizás porque es tan actual, irreverente y peligrosa. Mediante el empleo de la ciencia ficción y el esperpento denuncia los efectos del totalitarismo y poder extremos, donde el conocimiento, las artes y el pensamiento están constantemente sometidos a los tratamientos o lavados cerebro-rectales de los seres que habitan esta ciudad o país del futuro.

\section{La ciudad perdida de Juan Pablo Castro}

La ciudad de Los años perdidos (2013) es un espacio signado por el fracaso y poblado por personajes paranoicos víctimas de la rutina. Faustino Alcázar, con cincuenta años a cuestas, no es más que un esclavo que le rinde culto a un sistema capitalista del consumo. Para él no hay escape y prefiere refugiarse en un intersticio espacial y temporal donde la memoria claudica ante la amenaza del olvido. Por esta razón, la obra está construida a partir de la realidad ficticia doble: dos ciudades (Quito y Lisboa) y dos tiempos (pasado y presente) como antesalas de la desaparición total de las utopías y la esperanza.

Por un lado, se narra el espacio y el tiempo de la infancia y la juventud. Una urbe pequeña, en la "que nunca fue feliz" y donde solo reinaba la sordidez, la rutina, la violencia y el alcoholismo:

...cada vez que el padre aparecía por la casa, luego de terminadas las jornadas de ebriedad y lujuria, era Faustino, con un ridículo cerquillo sobre la frente, el que lo enfrentaba, sin palabras ni acusaciones, sino 
con el silencio y la aparente indiferencia. Ramona se enganchaba a su orgullo, pero días después terminaba por perdonar a su marido, convenciéndose a sí misma de que estaba enfermo, de que no era responsable de sus actos. Así, hasta un nuevo episodio de violencia, cuando el padre golpeaba la puerta del dormitorio de Ramona, donde ella y Faustino se refugiaban (Castro, 2013: 87).

La huida o el escape de los personajes de estos ambientes cerrados no se presenta sino como una solución urgentísima ante el agobio, la angustia y miseria en los que viven. Un caso similar ocurre con la imposibilidad del retorno o el regreso a la ciudad. Los personajes que retornan del "viaje" se sienten extraños, intrusos. Este principio de ajenidad, de no-patria, está ligado al extrañamiento con la urbe que le parece hostil y cruel. La urbe quiteña narrada por Castro es la propicia para alojar a seres mediocres, conformes con su estilo de vida que solo esperan la muerte. Estos personajes se transforman en arquetipos de la angustia en una sociedad "normalizada” y que impide cualquier tipo de trascendencia:

Caminaron un par de cuadras. El sol de la mañana se perfilaba detrás de los edificios añosos, antes oficinas de la burocracia estatal, y ahora devenidos en conventillos marginales. Un ruido amortiguado de autos, pitos y gritos callejeros empezó a develarse a medida que los dos, abrazados como borrachos, zigzagueantes todavía, llegaban a La Marín.

Entonces, mientras los buses lanzaban sus chorros de mugre, Frank, tapándose la boca con un pañuelo celeste, dijo:

-Oiga, amigo, ¿̇y cómo mierda terminamos aquifff? (Castro, 2013: 236).

Por otro lado, tenemos a Lisboa, ciudad fría con mucha lluvia y vientos primaverales donde sucede el enamoramiento de Faustino con Sofía veinte y cinco años atrás. Esta separación temporal provoca una sensación similar a la anterior, pues "la vida de los seres, en una ciudad antes [sea] borrascosa y [se transforme en un] lugar de páramos, tristeza y melancolía” (Castro, 2013: 12). En otras palabras, se construye una ciudad (la otra) en la que "tampoco fue feliz":

Ese "antes" y "después" suponen categorías narrativas fundamentales para contar la ciudad en sus sentidos y en sus tejidos históricos, coti- 
dianos, afectivos y utópicos; como también para representar los nuevos modos de experimentar la pertenencia a territorios escindidos. Un “antes" y "después" que colocan a los personajes, unas veces exiliados en un presente incomprensible; otras, en un pasado que sentirán como lo único existente; o como hipérbole de una situación límite, en la destrucción de la ciudad como utopía urbana (Ortega, 2002: 108).

Sin embargo, la significación de esta metáfora temporal recae en la desaparición de recuerdos que ubiquen la intención de hallar una salida real ante una urbe habitada por fantasmas, amenazas y violencias de todo tipo. Más bien, el tinte psicológico-existencialista del personaje provocado por el consumo de drogas, propone una batalla donde se contra-ataca: "el miedo acumulado en sus venas [dice el narrador] se convertía paulatinamente en risa nerviosa" (Castro, 2013: 162). Así que no cabía la posibilidad de exponer la construcción de un mundo ideal, sino que el registro de memoria de Faustino se tornó inmediato y oscuro donde sólo se podía percibir ““imágenes difusas" con "interminables gradas"” (Castro, 2013: 162) que repetían el fracaso y condición de perdedor del personaje.

Ahora bien, aunque la manifestación del vampiro no es propiamente un dispositivo de resistencia frente a esta atmósfera aletargadora; sin embargo, puede ser empleado como un factor que define a los protagonistas de la obra (Faustino y la femme fatal, Sofía), que miran en la noche el espacio y tiempo ideales para escapar de la rutina de la mañana. En este sentido, toda ciudad posee una “doble vida”: a la luz del día es cultural, ágil, dinámica, moderna, articulada. Por la noche, en cambio, el espacio de la euforia y del desenfreno: los espacios simbólicos han sido invadidos por el consumo y todas aquellas simulaciones que derivan de una situación límite que vive el ser contemporáneo que, al igual que la urbe, es fragmentario. Un espacio de la diferencia, el conocimiento, la subversión y la libertad. Conceptualmente se basa en la perspectiva de la vida cotidiana definida por De Certeau como la sociedad del espectáculo.

El vampiro surge como un ser mitológico que aparece en urbes nocturnas y de aspecto tenebroso. En la obra de Juan Pablo Castro, los personajes poseen estas características, pero manteniendo su esencia criolla. En el caso de Faustino no se evidencia la condición de vampiro a simple vista, pero se siente complacido por su estancia en las noches "desde su llegada a Portugal, convertido en un ser de nostalgia, [porque] encontró en las no- 
ches de juerga algún bálsamo para su desazón" (Castro, 2013: 168). Es decir, Faustino completamente adaptado a las calles nocturnas que le ofrecen entrenamiento vano, inexistente por la falta de propósito.

En el caso de Sofía o la Portuguesa como la llamaba Faustino, la condición vampírica es evidente. Este personaje cumple con los cánones de la mujer vampiro de finales del siglo XIX: ella es la "no muerta de piel blanca [...] que seduce, pervierte y, finalmente, mata a su víctima" (Castro, 2013: 85), pues Faustino describe obsesivamente sus características físicas, como su "blanca piel gélida" (Castro, 2013: 67) y su "mano que colgaba lívida, blancuzca, casi muerta" (Castro, 2013: 212), siempre desde la penumbra y empujado por el desprecio.

Luego de su primer encuentro, el protagonista se queda completamente prendado de ella, pero no se trata de un simple enamoramiento. Faustino está obsesionado con Sofía, incluso su amigo Margarito la nombra como "la famosa damisela que le tortura la mente" (Castro, 2013: 178), y eso queda corto a la presencia constante de la Portuguesa en la ya frustrada cabeza de él. Sofía se convierte, durante la estancia de Faustino en Portugal, en un motivo para alejarlo de su usual ensimismamiento. Su mente la mayoría de veces está ocupada pensando en Margarito con Sofía, imaginándose sus recurrentes encuentros sexuales.

La pensión de Sofía, donde vivió Faustino en su época de estudiante, también lo atemoriza, la define como "la espantosa pensión fantasmal donde, maldita sea la hora, le había tocado llegar" (Castro, 2013: 242), pero no sólo es el hecho de su apariencia sobrenatural. Es la morada deseada e inalcanzable a la que quiere llegar a ocupar y, además, porque este espacio representa el fin de sus anhelos, pues fue ahí donde él presentó a Sofía con Margarito. Pero también su frustración se deja ver en otros ámbitos: como profesor universitario, teniendo que lidiar con estudiantes desconectados y desinteresados; un escritor fracasado que nunca publicó su gran obra; las molestias que lo aquejan desde niño, con un padre maltratador y una madre sumisa y permisiva.

Los dispositivos con los que trata de disipar el miedo no sirven en verdad, pues él no puede tener sensación alguna. El alcohol y las prostitutas son formas temporales de huir de una realidad en la que no le importaría dejar de existir. Muchas veces a lo largo de la obra el protagonista imagina 
su muerte, y piensa, con una mezcla entre burla y tristeza, que la única que lo notaría sería la vecina por el putrefacto olor que despediría su cuerpo y un periodista que lo lanzaría a la fama post-mortem después de publicar su crónica amarillista:

El gordo no puede ya mirar cómo esos bramidos de fuego disuelven las cortinas, la alfombra, el papel tapiz y el cartel de una película en el que se puede ver a un hombre solitario, que mira, desde la ventana, una ciudad difuminada tras el manto del fuego y el humo. En el borde inferior de la imagen se lee: Los años perdidos. [...] Afuera caen gotas de fuego. Decenas de incendios acorralan la ciudad. Y, amortiguados por el estruendo que producen los choques de los autos, se escuchan los primeros alaridos humanos (Castro, 2013: 344).

Finalmente, su vida de cincuentón se encuentra encapsulada en una ciudad apocalíptica, espacio en extremo caluroso e insoportable que lo ahoga aún más. Quito representa, probablemente, toda la podredumbre que siente salir de su cuerpo muerto; una ciudad llena de entes, llena de burdeles, llena de nada, como cualquier otra urbe fatua; y que poco a poco es consumida por los incendios de verano.

\section{La ciudad-infierno de Huilo Ruales Hualca}

Desde el título mismo de la trilogía Los Kitos Infiernos de Huilo Ruales podemos imaginar a Quito ardiendo entre las llamas del apocalipsis. Esta alusión no puede sugerir otra cosa que el grave estado de enfermedad en el que se encuentra la ciudad donde habita el pánico entre sus habitantes condenados y sin esperanza. En el infierno todo es terror y desaliento; el miedo es infundido por demonios de distintos tipos y categorías (líderes políticos, burócratas, medios de comunicación, universidades, consumo...); sin embargo, la figura que reina y por lo tanto generadora principal del miedo es Zatanás, quien en Los Kitos Infiernos vendría a ser la ciudad misma: infierno y demonio a la vez; y sus habitantes: pequeños diablos que simultáneamente se temen e infunden miedo entre sí. Morada apocalíptica y maldita habitada por la delación, la violencia y la autodestrucción. Sin 
embargo, entre tanta podredumbre y mal olor existe aquel diminuto, completo y sagrado consuelo: el placer. Ante tanto asco, el placer (lo dionisíaco) le da sentido de la vida.

Efectivamente, en Edén y Eva podemos evidenciar la representación del miedo en esta horrible ciudad. Quito es el Infierno, el Inframundo, el Callejón sin salida; un mundo subterráneo en el que todos vivimos. Es una "metrópoli underground" habitada por la decadencia humana: locos, prostitutas, homosexuales, mendigos, alcohólicos, extranjeros y drogadictos, que en la obra se manifiesta mediante la presencia de Eva.

Este personaje representa el espacio gobernado por el poder, la amenaza y el miedo. Eva es confinada y controlada en un internado en Suiza porque "no es normal" y "piensa cosas raras". Inicialmente, el miedo está estrechamente relacionado con la sensación de vacío; y no solo eso, sino de un vacío "ordenado":

Suiza parece postal impresa en congelador. Postal sin gente, aunque haya gente. Hasta la basura es limpia. Hasta el desorden está ordenado. Todo es blanco, como decir vacío. El verdor de la pradera es blanco. El bosque es blanco. El lago de los cisnes no tiene cisnes ni es lago sino hielo. No se diga el hospicio blanco del internado. Todo es blanco, salvo el cielo, que es sucio. Miro por la ventana y es como si no mirara nada. Como si fuera ciega (Ruales, 2013: 218).

"Vacío ordenado", que degenera en la sensación de saber que alguien constantemente está vigilando. Eva se siente observada todo el tiempo y eso la cohíbe. El miedo se manifiesta al percibir que se está bajo el poder de alguien:

Ordenan, preguntan, ordenan, exigen respuestas, ordenan, castigan, se alejan. Cuando aparece Mademoiselle Claudette el mundo se paraliza y todas sentimos escalofrío. Es ella la inspectora de dormitorios. Es su voz que nos despierta y que a la hora de dormir nos quita la luz y el sueño. Sus gritos nos conducen a las duchas, al refectorio. Desde lejos se oyen los tacones de Mademoiselle Claudette entrando y saliendo de los pabellones, subiendo y bajando escaleras (Ruales, 2013: 219).

El internado establece un sistema de control específico que es infundir miedo a las estudiantes través de una inspectora, cuya presencia se mues- 
tra terrorífica. Michel Foucault ${ }^{1}$ menciona cómo ese tipo de sistemas permite a quienes manejan el poder, ejercer dominio sobre el otro. El temor a la geometrización europea es evidente cuando el filósofo francés afirma que la disciplina organiza un "espacio analítico". No solo es la presencia del orden, la cual desagrada a Eva, sino también hay que tomar en cuenta que la estructura de los panópticos (cárceles, internados, cuarteles, siquiátricos...), permite la absoluta vigilancia: "El objeto del principio de inspección es exactamente lo contrario: no les hace sólo sospechar sino tener la certeza de lo que todo lo que hacen se ve, aun si tal no es el caso" (Bentham, 2013: 14).

Cuando Eva por fin sale de vacaciones del internado, se hospeda donde su tío Kiefer y se siente mucho más cómoda, hasta se siente más segura: "La nieve vuelve al silencio más silencioso, pero aquí en la casa del tío me siento menos abandonada que en el internado" (Ruales, 2013: 225). Sin embargo, Eva nunca se sintió libre porque su tío procede a violarla: "Pero el tío es un animal gigantesco, un cíclope, un monstruo gimiente y pegajoso que se va hinchando y yo soy un pájaro vivo, cada vez más embalsamado" (Ruales, 2013: 228). En este sentido, el control se re-significa: no es "disciplinario" como sucede en el internado, pero igual se siente apresada y controlada por Kiefer.

Eva resiste al orden a través de la "Kofradía de los Poetas Desalados", constituida por personajes marginales y extraños. Eva frente al Edén, no es más que una larga metáfora que plantea dos cosas: la primera, el mecanismo de distanciamiento del individuo frente a la ciudad; y en segundo lugar, la posición del individuo con la estética underground. Estas determinaciones son, necesariamente, los dispositivos culturales que devuelven la subjetividad al individuo de cara a una "máquina maravillosa que, a partir de los deseos más diferentes, fabrica efectos homogéneos de poder" (Foucault, 1976: 187).

Huilo Ruales con Edén y Eva modela literariamente una imagen de la violencia y amenaza al sujeto urbano. No obstante, el miedo y el estableci-

${ }^{1}$ Michel Foucault, en Vigilar y castigar, habla del "arte de las distribuciones", mostrando distintas formas de disciplinar; es decir, cómo mantener el control de los cuerpos: "La disciplina exige a veces la clausura, la especificación de un lugar heterogéneo a todos los demás y cerrado sobre sí mismo" (1976: 145). 
miento de este, se generan más allá de las estructuras físicas como el propio Edén, los parques y cementerios. Eva, con un instinto de escape recurre a espacios alternativos, en este caso las letras y la cultura:

Eva la loca, agitada, escarba a dos manos en su bolso en pos de un revolver, un cuchillo, un spray de pimienta, pero lo que palpa es el trajinado librito Letters home de Sylvia Plath [...] También palpa los cuatro o cinco diminutos personajes chinos que son sus amuletos y, por último, el cepillo metálico de cabo terminado en punta (Ruales, 2013: 16).

Esta posición por la cual Eva se aleja del Edén es la poesía y el círculo de poetas desalados: "Por primera vez sentía la existencia dormida de su escritura poética y eso fue grandioso, como descubrir en el vientre un hijo que a veces se movía, que a veces le solicitaba vida" (Ruales, 2013: 335). No obstante, esta participación que le ofrece su entorno no es más que "la oportunidad de expresarse [...] manteniendo la estructura" (Benjamín, 2014: 60). Y esta estructura es el Edén, con su eje de poder llamado la Madama, que engendra temor a sus habitantes.

Por otro lado, la literatura como un sistema de ruptura entre el individuo y su sociedad sugiere, ineluctablemente, una dicotomía: marginalidad y civilización. Dicha bifurcación conlleva a la poesía a estéticas inverosímiles o denominadas en conjunto underground o subterránea. Incluimos una composición poética que represente esta figuración:

Hay dioses perros que nos ladran con asco o con miedo/ dioses atados como rotas mochilas al veterano de guerra que vive fascinado por la multiplicación de sus pústulas/ dioses llenos de pulgas y el hocico untado de inmundicias dulces/ dioses temblorosos, de rodillas de cristal/ dioses putas de nalgas fosforescentes surfeando en el smog/ dioses seniles fumando y sollozando en las cabinas telefónicas a la espera de la llamada imposible... (Ruales, 2013: 239).

Delleuze y Guattari (1978) plantean una literatura menor alrededor del panóptico de la civilización; por lo tanto, la performance: "una literatura que una minoría hace dentro de una lengua mayor" (28), tiende a denominarse underground. Al igual que Kafka y los judíos, La Kofradía de los poetas desalados se beneficia de la posibilidad del sistema que pretende dar voz a los marginales de los Kitos Infiernos, pues el lenguaje esperpén- 
tico también supone una visión irónica de la ciudad. El uso de palabras malsonantes provoca en el lector la polifonía del miedo.

Efectivamente, el lenguaje transgrede la realidad y crea una atmósfera que exalta los detalles grotescos de la urbe, cediendo al otro la capacidad inventiva para construir su propio sistema de comunicación que, en términos de Piglia, sería la lengua extranjera: "Además, estás puta, zorrita. Mírenla, está sonadísima. Ay, hijadelatripleputa, suelta, suelta. Gringa conchetumadre, toma. Quieta, te digo, grancabrona, toma, toma” (Ruales, 2013: 18). Esta poesía engendrada en los bares y librerías se deforma y refuerza por la lengua destructiva, blasfémica y caótica habitada por la risa. Un metalenguaje que busca una ciudad que falta.

\section{Quito, la ciudad del futuro: entre la ciencia-ficción y el miedo eterno en Ecuatox ${ }^{\circledR}$ de Santiago Páez}

Como sabemos, el relato de ciencia-ficción aborda problemáticas actuales pero contextualizadas en un futuro distante. Constituye un género que puede abarcar muchas posibilidades de creación para mostrar las sociedades y los mecanismos de control sobre ellas, a través de la representación de la ciudad. En este sentido, se convierte en una máquina del tiempo que nos conduce a un mundo incierto proyectado por lo general desde el presente, a partir de la especulación de una realidad determinada. La fantasía tecnológica, el ímpetu del futuro, la ilusión y el deseo de desarrollo, son parte del sueño eterno de perfección que el ser humano anhela.

La ciencia-ficción no solamente es una creativa posibilidad de narrar las relaciones del hombre con la sociedad y el universo, sino también para hacer actos de denuncia y anticipación. Se presta además para exponer diversos objetos tecnológicos que forman parte de la vida cotidiana de los seres humanos y cómo estos se ven afectados por su uso.

Es el caso de Ecuatox® (2013) del quiteño Santiago Páez, novela esperpéntica ${ }^{2}$ que construye una imagen desquiciadora de una ciudad de cemento y tecnología al servicio del poder. La obra se sitúa en el Ecuador de

\footnotetext{
${ }^{2}$ Género literario que se caracteriza por la presentación de una realidad deformada y grotesca y la degradación de los valores consagrados a una situación ridícula.
} 
2227, país que se encuentra envuelto en un régimen totalitario y absurdo del gobierno de Rafael Correa quien toma el cuerpo de un ciborg. Los diferentes temas que se abordan (educación, política, cultura, comunicación, legislación, entre otros) devienen en la construcción de una urbe artificial y del miedo, a partir de la construcción de una ciudad post-apocalíptica habitada por clones.

La ciudad de Quito de otros tiempos, de la anterior novelística ecuatoriana aparecía fragmentaria, dividida, invertida y travesti, poblada por diferentes rostros y lenguajes, que nos permitía percibir los particulares modos de apropiación de la urbe, ha sido reemplazada por la Urbe del Konocimiento (Yachay Tech ${ }^{3}$ ). Ciudad tecnológica, cuyas calles y avenidas reproducen la imagen del todopoderoso en medio de un ambiente surrealista y terrorífico:

Las calles de la Urbe del Konocimiento están pavimentadas con el desecho de las minas novoecuatorianas, por lo que son los mismos colores de los ríos del país: grises, amarillentas, rojas de óxido o cafés oscuras. Sobre semejantes calzadas se desplazaba una parvada de personas que, con paso lento, iba de un edificio a otro, mirando sus fachadas brillantes y cubiertas con imágenes del Líder. Los miembros de este grupo se detenían ante cada edificación y prorrumpían en exclamaciones de admiración y alegría, agitaban los brazos y se contoneaban (Páez, 2013: 95).

Sin embargo, lo artificial se extiende a todo el país y su riqueza. En su delirio por el poder, el Divino re-inventa un país compuesto por dioramas que provocan la ilusión de valles, ríos, bosques, selvas y praderas; una máquina controlada por una enorme computadora que se encuentra en la Cúpula Presidencial, en cuyo centro está el Primer Mandatario, que mira todo.

Efectivamente, el modo en que el narrador describe de forma irónica e irrisoria la realidad, da cuenta de que todo está observado por el gobierno, que se ha convertido en ser omnipotente y omnipresente. En lo social podemos encontrar un ejemplo claro de ridiculización de la realidad del Líder

3 Universidad-ciudad del conocimiento creada por el Estado el 12 de noviembre de 2013, destinada al desarrollo científico y tecnológico del país, y que alberga una gran cantidad de renombrados científicos extranjeros y nacionales. Actualmente, se replantean medidas para superar la crisis económica y académica en la que se encuentra. 
Esplendoroso y Sapientísimo que siempre ha manifestado que su misión es refundar el país pues todo lo que existió antes que él estuvo mal, siendo necesario "que una obra pública está terminada, como pertenece al pasado, hay que rehacerla, con extraordinaria rapidez" (Páez, 2013: 44).

El miedo y la amenaza están asociados en la actualidad a los discursos y a los teatros montados por los medios gubernamentales. El gobierno utiliza estos recursos con el fin de detentar el poder sobre la vida política y los civiles. Uno de los dispositivos para conseguirlo es la implementación de la teatralización o la cultura del espectáculo, que es la forma de ocultar o disfrazar la realidad, tanto en lo político, social y cultural, pues esta "dimensión emocional que tiene en América Latina como expresión popular no elude ni teme lo cursi o melodramático" (Aínsa, 2012: 29). En la obra, el miedo se evidencia en los excesos y estrategias de control del gobierno, caricaturizando y ridiculizando la realidad.

iy pensar que los izquierdistas pueriles de siempre rechazaron, en su momento, la Ley Orgánica de Intervención Intradomiciliaria! Este cuerpo legal garantiza la seguridad de la población que es vigilada por cámaras de video y diversos aparatos de escucha instalados en todos los ambientes del domicilio. La familia es protegida así (Páez, 2013: 25).

Los dispositivos de control que manejan los regímenes a través de instituciones político-estatales prevalecen mediante el lavado de las mentes con instrumentos tecnológicos. Así garantiza el culto a la personalidad de un líder que dicta leyes para su conveniencia y vigencia de sus convicciones. Por esta razón, el protagonista tiene que sujetarse a las normativas de control, mediante un chip que controla sus pensamientos y emociones. Y qué decir sobre los mandatos dramatizados del Ministerio del Amor por el Líder (Ministerio de Comunicación), que regulan lo que se tiene que leer, pensar, vestir y desear:

En esos peligrosos terrenos en los que antes se perdían los turistas, y aun los nacionales, ahora es imposible extraviarse: todo está a la vista; es más, el color verde agua de los uniformes de los ciudadanos resalta, alegremente, contra el gris del asfalto que en la actualidad, asépticamente cubre colinas, montañas y desfiladeros (Páez, 2013: 80). 
Ahora bien, estos dispositivos de control al servicio del poder yacen fielmente en el imaginario orwelliano. Una de ellas es cuando el Gran Hermano aparece como una figura emblemática en las "telepantallas"; sin embargo, su presencia se muestra como siniestra, donde "el espectador es sometido ya no a la reproducción de imágenes estereotipadas de las que nos habla Benjamin, sino a la alucinación colectiva de una imagen única, teatro óptico de un panorama terrorista giratorio" (Virilio, 2011: 80). En Ecuato $x^{\circledR}$ sucede de manera casi idéntica pues las sabatinas ${ }^{4}$ toman otras dimensiones:

[...] se vio gratamente interrumpida por el Holograma del Presidente, un dispositivo de imagen tridimensional que deben tener todas las casas de la nación y que reproduce al Líder Esplendoroso en todos sus detalles [...] de esta manera, los ciudadanos de Novo Ecuador pueden escuchar una y otra y otra y otra vez los discursos del Presidente Sapientísimo y sentir que sus estómagos se contraen, con amoroso terror, al observar su seño siempre fruncido, sus quijadas tensas y sus dientes apretados hasta rechinar de ira (Páez, 2013: 24).

Este elemento no es más que una muestra de la imposición y el hostigamiento del poder. Por otro lado, es interesante cómo los ciudadanos mantienen una relación de "amor-miedo" con Correa, idéntica a la de Winston cuando "se vence a sí mismo" y descubre que amaba al Gran Hermano. El lavado cerebral de los ecuatorianos responde a una admiración grotesca y un amor "infinito" hacia el Presidente, pero esto no significa que este amor está exento del miedo y terror más profundos. Esa persecución y vigilancia es una manera de impedir cualquier altercado o pensamiento que amenace la estructura de la sociedad del Novo Ecuador:

\section{REgGaeton Oficial y CORREÍsta \\ ¡Fuete! iFuete! iFuete! iFuete! \\ Presidente, Presidente \\ Dale correa a la gente}

\footnotetext{
${ }^{4}$ Nos referimos a las cadenas nacionales de radio y televisión que se transmitieron todos los días sábados de o9:00 a 13:0o hrs. Según el diario El Universo, durante los 10 años de gobierno, Rafael Correa realizó 518.
} 
Que por ti solo amor siente
Y no piensa divergente
iCastígala, castígala!
Presidente, Presidente.
iFuete! iFuete! iFuete! iFuete!
Y si alguien piensa en cosa
que no es la que a ti te gusta
Sácanos nomás la fusta
De tu mirada rabiosa.
iCastígala, castígala!
Presidente, Presidente
¡Denúncialo, denúncialo!
iFuete! iFuete! iFuete! iFuete!
En la feroz sabatina,
Ponnos su foto clarito
Con tu lengua jabalina
Ordena dejarlo frito
O colgado en una esquina
Por pensante al muy maldito.
iCastígala, castígala!
Presidente, Presidente
iFuete! iFuete! iFuete! iFuete!

(Páez, 2013: 39).

El miedo separa a la sociedad y a sus individuos. Este se manifiesta por los discursos empleados desde la campaña mediática de los gobiernos. Por lo tanto, los conatos nacionalistas, partidistas, contestatarios "conducen al rechazo del otro” (Tomé, 2005: 110) y provocan su exclusión. En la obra se plantea cómo los discursos que se usan sirven para generar un breve adagio social: separa y vencerás. Términos empleados en las sabatinas como "terroristas", "pelucones", "niños majaderos", “caretucos”, "bestias salvajes”, se constituyen en un verdadero idiolecto del miedo. En esta época no existen asociaciones ni comunidades estudiantiles ni gremiales. Todo funciona mediante mecanismos de vigilancia permanentes por parte de representantes reeducados constantemente a través de numerosos lavados cerebrorectales y la delación que está libre en las calles quiteñas, y por extensión en todo el Ecuador.

De esta manera, se puede decir que ya no hay heterogeneidad, sino una decadencia absoluta del pensamiento, hasta el punto que "los profesores ya 
no pierden el tiempo en reflexiones sobre preguntas de la humanidad. Ahora todos esos maestros corretean, vestidos con sus uniformes verde agua, agitando las manos llenas de formularios" (Páez, 2013: 64). Al final solo quedan los gritos paranoicos del dictador que vive la soledad más absoluta en una ciudad destruida con fierros retorcidos y olores metálicos nauseabundos. La raíz del miedo, tan institucionalizada por el Estado, provoca el pánico entre sus propios miembros liderados por el Divino, despojado de toda humanidad. La novela como discurso profético subvierte los procesos de enajenación instalados por la máquina del poder absoluto representado por el Dictador que mira el complot en todo lado, siendo presa, él mismo, de un delirio de persecución que hay que censurar.

En las obras de los tres autores ecuatorianos hemos podido analizar cómo se construye el miedo en la urbe quiteña en la novelística ecuatoriana de los últimos años. Entre las constantes, podemos anotar: a) Existe una relación secreta entre la construcción del miedo urbano con el poder de un Estado autoritario. Los relatos resisten el totalitarismo mediante la creación de personajes e historias que buscan un nuevo hábitat que les posibilite la trascendencia y la libertad. Términos como ciudad sucia, ciudad mugre, ciudad horrible provocan el deseo de una nueva ciudad solidaria, heterogénea y múltiple. b) Las obras trabajan la ciudad post-apocalíptica a causa del fuego. Existe un proyecto político y estético por construir un nuevo lenguaje (convencional y artístico) que articule una real comunicación entre los seres que habitan los diferentes espacios, para pensar en un proyecto de nación. En otras palabras, buscar la ciudad que falta. c) Las obras (sobre todo de Ruales y Páez) están construidas a partir de la estética del esperpento, precisamente para dar esa imagen de hartazgo frente a los acontecimientos sociales, políticos y culturales del Ecuador en los últimos años. Particularmente en la novela de Páez, a través del recurso de la ciencia ficción se construye una imagen terrorífica del Presidente Correa que funda su propio lenguaje y su propia ciudad. d) Existe un sentido benéfico de la palabra, la literatura y la cultura: crear alteridades y provocar la libertad del pensamiento. En otras palabras, frente a los dispositivos de control y dominio por parte del Estado autoritario, la literatura y la palabra 
conspiran, mediante dispositivos de resistencia (risa, esperpento, cienciaficción), para encontrar felicidad, como afirma Bauman (2007): "El demonio del miedo no será exorcizado hasta que encontremos (o, para ser más exacto, hasta que construyamos) nuestra libertad de elección" (42). Ciudad apestada por el miedo que se deconstruye en el lenguaje literario que la fábula, la reinventa y la busca.

\section{Referencias}

Aínsa, F. (2012). Palabras nómadas. Nueva cartografía de la pertenencia. Madrid: Vervuert Iberoamericana.

Bauman, Z. (2006). Confianza y temor en la ciudad. Barcelona: Arcadia. . (2007). Tiempos líquidos. Vivir en una época de incertidumbre. Buenos Aires: Tusquets Editores. . (2013). Vigilancia líquida. Buenos Aires: Paidós.

Benjamin, W. (2014). La obra de arte en la era de su reproductibilidad técnica $y$ otros textos. Buenos Aires: Godot.

Bentham, J. (2013 [1791]). El panóptico. Buenos Aires: Editorial Cuadrada.

Castro, J. P. (2013). Los años perdidos. Quito: Alfaguara.

Cortés, J. M. (2010). La ciudad cautiva. Control y vigilancia del espacio urbano. Madrid: Akal.

Delumeau, J. (2001). Miedos de ayer y hoy. Conferencia inaugural del seminario "La construcción social del miedo. Una lectura de la experiencia urbana en ciudades contemporáneas", realizado por la Corporación Región en Medellín del 15 al 17 de agosto de 2001. Traducción de Mathieu Bernard, Alianza Francesa y Ramón Moncada, Corporación Región, agosto de 2001. Disponible en http://bibliotecavirtual.clacso.org.ar/ar/libros/region/reflexiones.pdf.

Delleuze, G. y Guattari, F. (1978). Kafka. Por una literatura menor. México D.F.: Ediciones Era.

Foucault, M. (1976). Vigilar y Castigar. Argentina: Siglo Veintiuno Editores.

Lotman, Y. (2008). Caza de brujas. La semiótica del miedo. Revista de Occidente, $329,5-33$.

Mongardini, C. (2007). Miedo y sociedad. Madrid: Alianza Editorial.

Ortega, A. (2002). La representación de Quito en su literatura. En M. Moraña (ed.), Espacio urbano, comunicación y violencia en América Latina (pp. 107-126). Pittsburg: Universidad de Pittburg.

Páez, S. (2013). Ecuatox®. Quito: Paradiso Editores.

Reguillo, R. (2000). La construcción social del miedo. Narrativas y prácticas urbanas. En S. Rotker S. (ed.), Ciudadanías del miedo. Caracas: Nueva 
Sociedad. Disponible en https://es.scribd.com/doc/97232848/RossanaReguillo-La-Construccion-Social-Del-Miedo.

Rodríguez, E. (2014). Temor y control. La gestión de la inseguridad como forma de gobierno. Buenos Aires: Futuro Anterior Ediciones.

Ruales Hualca, H. (2013). Edén y Eva. Quito: Eskeletra.

Sánchez, R. (2002). La ciudad: el poder y lo social. En C. A. Torres, F. Viviescas y E. Pérez (eds.), La ciudad: hábitat de la diversidad y complejidad (pp. 302-316). Bogotá: Unibiblos.

Tomé, S. (2005). Los miedos en la ciudad. En La ciudad y el miedo (pp. 109114). Barcelona: Departamento de Geografía. Universidad de Oviedo.

Virilio, P. (2011 [2004]). Ciudad pánico. Buenos Aires: Capital Intelectual.

Zarone, G. (1993). Metafísica de la ciudad: encanto utópico y desencanto metropolitano. Valencia: Pre-textos. 